\title{
Personality and job engagement among municipal workers in the Eastern Cape province, South Africa
}

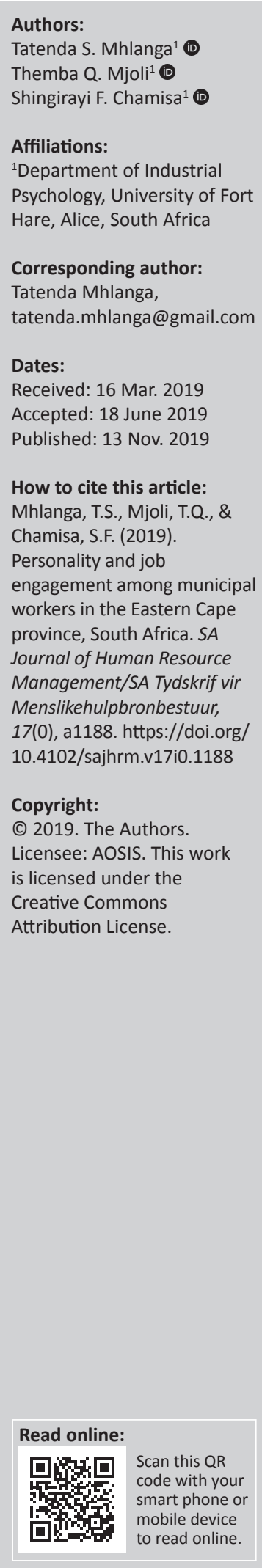

Orientation: Although researchers have discovered many of the beneficial and positive consequences of job engagement, little is known about the multitude of antecedent factors that lead to employee engagement such as personality.

Research purpose: The aim of the study was to investigate the relationship between the big five personality traits and job engagement among municipal workers.

Motivation for the study: The motivation of this study is to examine the relationship between personality and psychological conditions. It was premised on previous research that personality is associated with many employees' behaviours.

Research approach/design and method: The present study employed a quantitative, crosssectional research design by using a questionnaire on a sample of 403 district municipal workers in the Eastern Cape province, South Africa.

Main findings: The study findings show that openness to experience, conscientiousness, extraversion and agreeableness had a positive relationship with job engagement, whereas neuroticism has a negative relationship with job engagement. Municipalities and educational qualifications had an impact of job engagement.

Practical/managerial implications: The study recommends managers to switch from an intervention-based focus to a selection-based focus as municipalities can maximise their resources by being able to better predict job success early in the selection process as opposed to trying to maximise the performance on a continual basis through interventions.

Contribution/value-add: This study adds to an understanding of the influences of personality on work outcomes such as job engagement, giving areas for exploration in coaching or feedback interviews based on personality assessment.

Keywords: personality; job engagement; employee engagement; municipal workers; Eastern Cape.

\section{Introduction}

The efficiency of the public service delivery depends on the performance of the public employees. Because of high protest in the Eastern Cape because of poor service delivery, it is crucial to understand if the employees are engaged in doing their work. Municipal workers need to be engaged in their work as this will enhance good service delivery, which will increase the socioeconomic status of the citizens. Employee engagement has important ramifications for operating results, budget management and the public's satisfaction with government. Crabtree (2013) found that only $13 \%$ of the employees were engaged globally, whereas $4 \%-15 \%$ were engaged in South Africa. Although researchers have discovered many of the beneficial and positive consequences of job engagement, little is known about the multitude of antecedent factors that lead to employee engagement such as personality.

As a research field, employee engagement has seen remarkable growth in the recent era (Jin \& McDonald, 2016); however, in assessing the body of research related to employee engagement, Wood, Kim and Khan (2016) determined that the field of study is still relatively young. Despite growth in the exploration of the subject, the body of research related to employee engagement still lacks depth, breadth and adequate explanatory theory (Bailey, Madden, Alfes, \& Fletcher, 2017). Wollard and Shuck (2011) noted a general lack of validation studies within the employee engagement body of research and specifically suggested a need for quantitative testing of antecedents to employee engagement across a variety of organisational sectors and settings. By adding both breadth and depth to the field, this research study is positioned to contribute to the body of work in employee engagement research. 
Moshoeu (2017) focused on personality and work balance as determinants of employee engagement among management staff. He recommended that a further study on the study variables and to include lower level employees, which this study achieved. He also recommended having a larger sample from a single organisation as well as in terms of gender, generational cohort, functional job level, economic sector, educational qualifications, tenure, parental status and marital status, to achieve representative and generalised research findings. The study focused on the impact of demographics on the study variables among the municipalities in the Eastern Cape.

There is potentially much to be gained from studying the correlation between personality type and job engagement. The question remains as to why employees, when working under comparable conditions, display signs of job engagement, whereas others display a few or no signs of job engagement (Wilson, 2009). Individual factors such as personality traits have been minimally investigated in relation with job engagement, whereas organisational factors have been researched thoroughly (Saks \& Gruman, 2014). Noesgaard (2016) suggests that individual differences should occupy more space in the work engagement literature and should not be underestimated. According to Rothmann and Joubert (2007), it is crucial to recognise that both organisational and individual aspects are continually inducing engagement; hence, additional enquiry is required to identify individual components of engagement (Rich, 2006). As such, attention on individual characteristics such as personality will add value to the present study on job engagement especially to municipalities.

Although job engagement is an old and widely researched concept, its conception as defined by Kahn (1990) is relatively new in behavioural research and has not been widely researched. According to Kahn (1990), job engagement involves the binding of employees to their task by expressing themselves physically, cognitively and emotionally when performing their roles. Further studies on the Kahn's (1990) engagement concept are necessary as they differ from the previous engagement scales which have roots in the burnout literature which Schaufeli, Salanova, González-romá and Bakker (2002) later confirmed that job engagement is not relatively the exact opposite of burnout. Henceforth, it is a necessity that this concept and its connection to personality be examined in the projected research. The majority of research has focused on employee engagement as a predictor of work and organisational outcomes or on organisational and work factors that influence job engagement leaving out some factors that affect job engagement indirectly (Men, 2015). The role of individual differences has been fragmented and limited, hence the focus of personality in this study.

\section{Problem statement}

The demand for staff who show initiative are motivated to outspread their energies outside the boundaries of the job description, and are dynamically engaged as the characteristics of what is sought after in the 21st-century workplace (Leiter \& Bakker, 2010). Employee engagement has been identified as a significant contributor to positive organisational outcomes (Devi, 2017) and considered to be the most influential factor to measure an organisation's vigour and orientation towards superior performance. Therefore, job engagement is crucial to the survival of organisations as noted by Juan (2010) who indicates that when employee engagement is not effectively managed, firms lose between $5 \%$ and $15 \%$ of sales revenue. As a result, most researchers have attempted to explain why some employees are less engaged than others. The preponderance has primarily focused on identifying characteristics of the work environment that influence or contribute to job engagement. Less research (Inceoglu \& Warr, 2012) has focused on identifying the individual characteristics inherent in employees who promote job engagement. Therefore, the study goal is to address the problem of why some employees are more engaged than others by focusing on the personality of the employees.

In addition, another problem is that much of the contemporary literature focuses on the private sector (Ziapour \& Kianipour, 2015) where causality and construct relationships are informed by financial data and more readily available performance metrics. Antecedents of work engagement such as autonomy, transparency and feedback may be less evident in public organisations (Pollitt \& Bouckaert, 2011). Employees in the public sector can be less engaged and less devoted to their organisation than employees in the private sector (Agyemang \& Ofei, 2013). This might be because of unique encounters public sector employees face such as resource shortages, political influence and less management discretion for financial incentives (Jin \& McDonald, 2016). Hence, there is a need to focus more studies on the public sector.

Also, a considerable number of engagement studies were conducted abroad and a few in Africa, especially South Africa. Therefore, there is a necessity to identify and understand the main aspects that prompt employee engagement within the public sector and by extension might contribute to enhanced organisational effectiveness. Although strategies for increasing engagement are available in the popular press and management publications, they might not conform to rigorous, evidencebased academic standards. Trustworthy data and information are critical because the work of government employees affects citizens' lives through a variety of essential functions such as social services, health care, utilities and law enforcement.

\section{Objectives of the study}

The main objective of the study is to augment knowledge and the relationship between personality and job engagement. It also seeks to find out if a combination of any two or more personality traits will explain a higher proportion of variance in job engagement and investigate the impact of study demographics on job engagement. 


\section{Literature review Theoretical perspective}

\section{Kahn's theory of engagement}

Kahn's (1990) employee engagement theory is grounded in role theory with the view that the process of engagement involves individuals expressing themselves in their job tasks in a way that is consistent with their true selves or in the case of disengagement, withdrawing and defending their selves from their work role. Individuals usually bring or eradicate themselves from task behaviours or performances. According to Kahn's (1990) theory, the engagement or disengagement is fuelled by employee's evaluations of three primary psychological conditions: meaningfulness, safety and availability that are influenced by numerous critical aspects within the work setting.

Therefore, when the job task is important, the organisational environment is secure and sufficient resources are accessible, employees have a tendency to illustrate dynamic, full exhibitions to their work tasks (Kahn, 1990) through physical, cognitive and emotional engagement (EE). The cognitive facet of job engagement is concerned about how employees perceive the organisation, management and the working environments. The emotional feature focuses on how workers feel about each of the three aspects and their standpoint on the organisation and its management. Physical engagement (PE) can be noted through the exertion of energy towards achieving a task.

Appropriately, Kahn's main aim was to distinguish those mental components that were powerfully sufficient to outlive the extent of individual variances (Kahn, 1992). Afterwards, Kahn recommended that personality differences might still matter as they might influence an individual's dispositions to either engage or disengage (Kahn, 1992). Therefore, Kahn suggested that the investigation of personal aspects associated with engagement may be a critical subject for future inquiring. In this manner, individual differences can be followed back to individuals having different personality characteristics, which make their conduct contrast even when they are in the same work environment. People whose characteristics and necessities partner the demands of the situation will be able to engage themselves at work (Kahn, 1990).

\section{Five-factor model}

Five-factor model (FFM) developed by Lewis Goldberg (1990) is an appealing model of use within the personality literature and research as it integrates an extensive collection of personality variables to a common language and framework for personality researchers. It also provides a comprehensive overview of the factors that are made up of individual differences. The five orthogonal personality factors which the FFM focused on are stability, extraversion and openness to experience, conscientiousness and agreeableness. It can be argued that people behave in different ways because of their diverse personality behaviours, which later affect their behaviours. Thus, it will be used for the study to understand how people with different personality types behave differently in the same situations which will lead to job engagement or disengagement.

\section{Conceptual literature review Job engagement}

Job engagement (Fitzpatrick, 2017) can be defined as a:

$[P]$ ositive, energized state of mind that stems from both a cognitive and an emotional investment of personal energy that is focused on transforming a work task, a team goal, and/or an organisation outcome into a meaningful business objective. (p.7)

Job engagement is a condition of being emotionally and rationally involved in jobs that inspire workers to perform satisfactorily (Habraken, 2013, p. 12). Employees are considered a vital resource in any organisation and with the increase in talent war, there is a need for an organisation to safeguard that apart from enticing the finest talent, they can preserve these gifted employees. However, being able to retain employees is still not sufficient as one may have the finest capacity but might not be zealous about their jobs (Kamau \& Sma, 2016). It can be noted from Gallup Group and also by Martins and Nienaber (South African Board for People Practises, 2014) a South African sample demonstrated that $46 \%$ of the employees were not engaged and $45 \%$ were actively disengaged (45\%).

According to Kahn (1990), engagement is defined as a state in which individuals express their complete self physically, cognitively and emotionally in their tasks.

\section{Physical engagement}

Rich (2006) gave a summary of PE according to the Kahn's concept of job engagement as the force attempted on another person's job or a way of channelling one's physical efforts towards the accomplishment of a specific undertaking.

\section{Emotional engagement}

Emotional engagement refers to the emotional connection that an employee feels towards the organisation and tends to influence conduct and the level of exertion in businessrelated exercises. The more engagement an employee is with the organisation, the more exertion they set forth (Business Dictionary, 2015).

\section{Cognitive engagement}

Kahn's (1990) initial conceptualisation of cognitive engagement (CE) was acquired from an employee's resolve as to whether they believed that their work was meaningful and safe, and in addition whether the essential resources are accessible to finish their work.

\section{Personality}

The American Psychological Association describes personality as individual differences in terms of how people think, feel and 
behave (American Psychology Association, 2017). It incorporates an individual's relatively constant feelings, opinions and behavioural patterns. Every person has an inimitable disposition that separates him or her from other individuals, and understanding someone's personality provides evidence on the manner in which an individual is expected to behave in different circumstances (Alanoud \& Amir, 2016).

After South Africa gained its democracy, certain legislations were passed such as the Labour Relations Act of (1995) and the Employment Equity Act of (1998). The former act is dutybound for organisations to have precise unbiased standards by which interviewees for a job are assessed, whereas the latter act forbids personality tests until proved to be valid, consistent, impartially and unprejudiced towards some employees. Personality test utilisation when choosing a job candidate has extremely increased in South Africa as shown by many studies conducted in this regard (Davis, 2013).

Everyone has a unique personality that separates one from another, and understanding an individual's personality can give inklings on how that individual is likely to act and feel in a variety of circumstances (Alanoud \& Amir, 2016). The study looked at the big five personality traits that are as follows.

\section{Emotional stability - Neuroticism}

Neuroticism refers to an individual's emotional stability and the overall predisposition to experience adverse effects of the environment (Taylor \& De Bruin, 2006), whereas emotionally stable individuals are more assured, calm and skilled in handling demanding situations.

\section{Extraversion - Introversion}

Extraversion trait refers to people who are usually confident to pursue social relationships as well as to revel in optimistic sentiments (Taylor \& De Bruin, 2006), whereas introverts are people of few words, quiet, keep to themselves and thoughtful.

\section{Openness to experience - Closeness to experience}

A person with high levels of openness to experience love learning and fine arts, participate in an artistic profession and enjoy meeting new people, whereas people with closeness to experience are usually realistic, emotionally shallow and down to earth (Lebowitz, 2016).

\section{Agreeableness - Rudeness}

Agreeable individuals are kind, sympathetic and tender and are associated with unselfishness and pro-social conduct (Gerlach, Herpertz \& Loeber, 2015). Individuals scoring low in agreeableness are viewed by others as untrustworthy because they are usually uncaring, impolite, ill-tempered, aggressive and cynical.

\section{Conscientiousness - Undependability}

Conscientiousness refers to the level of effectiveness and competence within an individual with which he or she schedules, monitors and performs tasks (Taylor \&
De Bruin, 2006). Undependable individuals are disorganised, untrustworthy and less reliable.

\section{Empirical literature review}

In terms of emotional stability or neuroticism, research demonstrates that employees scoring high in emotional stability have a more prominent possibility of experiencing job engagement than employees low in emotional stability (Reinke \& Chamorro-Premuzic, 2014; Woods \& Sofat, 2013). They find it less demanding and more characteristic to put terrible past encounters and pay attention to their present performance positively.

In terms of conscientiousness, another study has reported similar findings that individuals who are inclined to be hard-working, reliable, self-disciplined and optimistic are able to translate their work engagement into increased individual job performance (Bakker, Demerouti, \& Brummelhius, 2012). Therefore, it was determined that employees who are high in conscientiousness have solid organisational skills and have a solid awareness of others' expectations and are more than answerable to put liveliness into their work, feel a robust sense of expert efficacy and are most likely to complete the job (Steger, Litman-Ovadia, Miller, Menger, \& Rothmann, 2013).

Li, Gao, Shen and Liu (2014) found that high levels of extraversion and emotional stability were frequently found to be connected with job engagement indicators which might be because of extroverts being energetic, passionate and achievement-oriented. Similarly, Handa and Gulati (2014) explored the relationship between extraversion and conscientiousness personality and employee engagement among 333 frontline personnel in the organised retail industry and found a positive relationship between extraversion and conscientiousness personality traits and employee engagement. Moshoeu (2017) focused on personality and work balance as determinants of employee engagement among management staff in a Web-based survey in the various industries in South Africa. She found significant relationships between the variables such as agreeableness, conscientiousness, emotional stability and employee engagement.

\section{Literature gap}

It can be noted that the above literature is mainly from international studies, and not conducted in South Africa. Most of the studies conducted in South Africa mainly focused on one variable, not on both personality and job engagement. Most of the studies conducted in South Africa mainly used the Utrecht Work Engagement Scale, which is usually associated with burnout. In addition, a few used Goldberg et al.'s (2006) personality measurement. The research study intends to extend the current literature on employee engagement in municipalities in South Africa, by empirically investigating the impact of personality traits on employee engagement. This might be the first study to the researcher's knowledge that attempts to investigate the relationship between personality traits measured by the 50 -item 
International Personality Item Pool (IPIP) developed by Goldberg et al. (2006) and employee engagement measured by the job engagement scale (JES) developed by Rich, Lepine and Crawford (2010) among municipal workers in the Eastern Cape province (ECP) of South Africa.

Most research performed on job engagement and personality have recommended that research needs to be performed with other samples for further studies to compare the results (De Villiers, 2015; Hale, 2016). In addition, most researches have been conducted in private sectors, hence the need to have more research on public government sector to make it more generalisable. Jin and McDonald (2016) suggested that employee engagement in the government public sectors is a topic that remains under-researched. This study adds to the scholarly research by providing results related to employee engagement and personality within an under-researched sector. Furthermore, Shaban (2018) in his study on personality and job engagement recommended future research to address the impact of personality on employee engagement of the employees in the public sector.

The following section will proceed in explaining the methodology of the study as well as the results obtained from the data.

\section{Research design}

\section{Research approach}

The quantitative method is well suited for the examination of relationships between variables and was therefore determined to be suitable for this study. A cross-sectional quantitative research design was followed to achieve the study objectives.

\section{Research method \\ Research participants}

The target population of the study consisted of all the municipal workers from six district municipalities in the ECP, which are Alfred Nzo District Municipality (ANDM), Cacadu District Municipality, Chris Hani District Municipality, Amathole District Municipality (ADM), Joe Gqabi District Municipality and O.R. Tambo District Municipality. A total simple random sample of 403 municipal employees was chosen for the study.

\section{Measuring instruments}

The data were collected by using a questionnaire, which consisted of three sections that are the personality questionnaire, job engagement questionnaire and demographical questionnaire developed by the researcher. As such information was collected on race, gender, marital status, age, tenure, occupational level and educational level.

\section{International personality item pool}

The personality traits, neuroticism, agreeableness, conscientiousness, openness to experience and extraversion were measured by using the 50-item IPIP (Goldberg et al., 2006). Every single trait was measured by 10 items on a fivepoint Likert type ( 1 - very inaccurate and 5 - very accurate) scale. The traits were found to have the following alpha coefficients: conscientiousness (0.79), extraversion (0.87), agreeableness (0.82), openness to experience (0.84) and neuroticism (0.86) (Goldberg et al., 2006).

\section{Job engagement scale}

Rich et al. (2010) developed the 18-item JES based on Kahn's conceptualisation. Employees were requested to show the level to which they are engaged with their jobs on a fivepoint Likert-type scale ranging from 'strongly disagree' (1) to 'strongly agree' (5). The internal consistency coefficient for the PE dimension was $\alpha=0.91$; for EE, it was $\alpha=0.94$; and for the CE dimension, it was $\alpha=0.95$ (Ongore, 2013).

\section{Research procedure}

Questionnaires together with blank envelopes were handdelivered to the respondents. Questionnaires included a cover page with instructions to the participants and information on the assessments and the research. The consent form was also included in the questionnaire, which participants were requested to sign. Participants were given one week to complete and return the completed questionnaires by dropping them off in a marked box at the human resources department office.

\section{Statistical analysis}

Statistical Package for the Social Sciences (SPSS) version 24 was used for analyses. Tests were carried out at either $1 \%$ or $5 \%$ level of significance. A descriptive analysis was used to describe the study's demographic features. A correlational analysis coupled with a simple linear regression analysis was utilised to determine whether personality traits exert a significant effect on job engagement.

\section{Ethical consideration}

Permission to conduct the research on the district municipalities was obtained from the municipal manager and the university ethics committee. The researcher ensured that all participants were informed wholly of what the study and it was voluntary. Privacy, confidentiality, anonymity and dignity were upheld at all times.

\section{Results \\ Demographical information}

The study consisted of 52\% male employees, and $80 \%$ were black African. Most of the respondents were in the age group of $31-40$ years, and $45 \%$ of the respondents were single in terms of their marital status. The main qualification of the respondents was a diploma, followed by a degree. The majority of the respondents worked on level 6-10 salary level in the municipality, and most of them have been working in the municipality for 1-5 years. Seventy per cent of the employees were permanently employed. 
TABLE 1: Descriptive statistics and reliability statistics of the scales.

\begin{tabular}{|c|c|c|c|c|c|c|c|c|c|c|}
\hline \multirow[t]{2}{*}{ Variable } & \multirow[t]{2}{*}{$N$} & \multirow[t]{2}{*}{ Min } & \multirow[t]{2}{*}{ Max } & \multirow[t]{2}{*}{ Mean } & \multirow[t]{2}{*}{ SD } & \multicolumn{2}{|c|}{ Skewness } & \multicolumn{2}{|c|}{ Kurtosis } & \multirow[t]{2}{*}{$\alpha$} \\
\hline & & & & & & Statistic & SE & Statistic & SE & \\
\hline Job engagement & 403 & 1.06 & 5.00 & 4.07 & 0.69 & -0.78 & 0.12 & 0.98 & 0.24 & $0.93 * *$ \\
\hline Physical & 403 & 1.00 & 5.00 & 4.11 & 0.73 & -0.84 & 0.12 & 0.75 & 0.24 & $0.83^{* *}$ \\
\hline Emotional & 403 & 1.00 & 5.00 & 4.09 & 0.80 & -0.85 & 0.12 & 0.57 & 0.24 & $0.86 * *$ \\
\hline Cognitive & 403 & 1.00 & 5.00 & 4.03 & 0.78 & -0.79 & 0.12 & 0.61 & 0.24 & $0.87 * *$ \\
\hline Extraversion & 403 & 1.00 & 7.00 & 5.65 & 1.22 & -1.10 & 0.12 & 0.82 & 0.24 & $0.70 * *$ \\
\hline Agreeableness & 403 & 1.00 & 7.00 & 4.66 & 1.35 & 0.16 & 0.12 & -0.92 & 0.24 & $0.78 * *$ \\
\hline Openness & 403 & 1.80 & 7.00 & 5.66 & 1.19 & -0.92 & 0.12 & 0.43 & 0.24 & $0.76 * *$ \\
\hline Neuroticism & 403 & 2.40 & 4.38 & 3.32 & 0.31 & 0.28 & 0.12 & -0.03 & 0.24 & $0.73 * *$ \\
\hline Valid $N$ (list wise) & 403 & 1.00 & 4.50 & 2.85 & 0.70 & -0.36 & 0.12 & -0.33 & 0.24 & - \\
\hline
\end{tabular}

$\mathrm{SD}$, standard deviation; $\mathrm{SE}$, standard error

**, Significantly reliable.

\section{Reliability analysis}

Cronbach's alpha was applied to measure the instrument's internal consistency. The Cronbach's alpha coefficient for the JES and IPIP are between $\boldsymbol{\alpha}=0.93$ and $\boldsymbol{\alpha}=0.70$. This means that the measuring scales are reliable as presented in Table 1.

\section{Descriptive statistics}

Table 1 shows the descriptive statistics of the study variables. It shows that the mean levels of the main variables that are job engagement $($ mean $=4.07 ; \mathrm{SD}=0.69)$, conscientiousness $($ mean $=5.44 ; \mathrm{SD}=0.96)$, agreeableness $($ mean $=4.66 ; \mathrm{SD}=$ $1.35)$, openness (mean $=5.66 ; \mathrm{SD}=1.19)$ and extraversion (mean $=5.65 ; \mathrm{SD}=1.22)$ were all high for the study sample. Only neuroticism (mean $=3.32 ; \mathrm{SD}=0.31$ ) was moderately high, which shows that the respondents somewhat agreed with the measuring items of the variables.

\section{Demographic differences on job engagement}

It was also imperative to test for demographical differences on job engagement within our sample as they have been major inconsistencies in the past literature. Maslach and Leiter (1997) suggested that demographics such as age, work experience, sex and occupation type makes interpreting demographic variables in relation to engagement a challenging task because of a lack of research evidence. Tables 2 and 3 show the results of a one-way analysis of variance (ANOVA) with post hoc Tukey honestly significant difference (HSD) test for comparing mean differences of ordinal categorical demographic variables on job engagement dimensions. Only two demographics in this study had an impact on job engagement. Race, age, gender, job status, marital status, race and tenure did not show any significant difference on the mean levels of job engagement.

Job engagement had statistically significant differences on level of education $(F=4.18 ; p=0.001)$ and municipalities $(F=$ 12.77; $p \leq 0.0001)$. The Tukey post hoc test shows that employees who had a certificate qualification (mean $=4.16$, $n=67$ ) have significantly higher levels of job engagement
TABLE 2: Statistically mean differences of job engagement and demographics.

\begin{tabular}{lccccccc}
\hline Source & \multicolumn{4}{c}{ Municipality } & & \multicolumn{3}{c}{ Qualifications } \\
\cline { 2 - 4 } \cline { 7 - 8 } & DF & $\boldsymbol{F}$ value & $\operatorname{Pr}>\boldsymbol{F}$ & & DF & $\boldsymbol{F}$ Value & $\operatorname{Pr}>\boldsymbol{F}$ \\
\hline Job engagement & 5 & 12.78 & $0.000 * *$ & & 5 & 4.18 & $0.001 * *$ \\
Physical & 5 & 13.14 & $0.000 * *$ & 5 & 4.97 & $0.000 * *$ \\
Emotional & 5 & 8.93 & $0.000 * *$ & 5 & 2.31 & $0.043^{*} *$ \\
Cognitive & 5 & 9.15 & $0.000 * *$ & 5 & 3.35 & $0.006 * *$ \\
\hline
\end{tabular}

Anova- $F(\mathrm{Sig})$ implies ANOVA analysis and shows whether there is a statistically significant difference between the group means.

**, Significant mean differences.

TABLE 3: Mean differences of job engagement and demographics.

\begin{tabular}{lllll}
\hline Variable & \multicolumn{4}{c}{ Mean Tuke ${ }^{\mathrm{HSD}}(\boldsymbol{n})$} \\
\cline { 2 - 5 } & $\begin{array}{c}\text { Job } \\
\text { engagement }\end{array}$ & $\begin{array}{c}\text { Physical } \\
\text { engagement }\end{array}$ & $\begin{array}{c}\text { Emotional } \\
\text { engagement }\end{array}$ & $\begin{array}{c}\text { Cognitive } \\
\text { engagement }\end{array}$ \\
\hline Alfred Nzo & $(73) 3.58^{\mathrm{a}}$ & $(73) 3.55^{\mathrm{a}}$ & $(73) 3.57^{\mathrm{a}}$ & $(73) 3.60^{\mathrm{a}}$ \\
Chris Hani & $(69) 4.23^{\mathrm{b}, \mathrm{c}}$ & $(69) 4.28^{\mathrm{b}}$ & $(69) 4.20^{\mathrm{b}, \mathrm{c}}$ & $(69) 4.20^{\mathrm{b}, \mathrm{c}}$ \\
Joe Gqabi & $(75) 4.05^{\mathrm{b}, \mathrm{c}}$ & $(75) 4.12^{\mathrm{b}}$ & $(75) 4.10^{\mathrm{b}, \mathrm{c}}$ & $(75) 3.93^{\mathrm{a}, \mathrm{b}}$ \\
OR Tambo & $(60) 4.36^{\mathrm{c}}$ & $(60) 4.33^{\mathrm{b}}$ & $(60) 4.39^{\mathrm{c}}$ & $(60) 4.35^{\mathrm{c}}$ \\
Sarah Baartman & $(62) 4.03^{\mathrm{b}}$ & $(62) 4.14^{\mathrm{b}}$ & $(62) 4.01^{\mathrm{b}}$ & $(62) 3.95^{\mathrm{a}, \mathrm{b}}$ \\
Amathole & $(64) 4.24^{\mathrm{b}, \mathrm{c}}$ & $(64) 4.33^{\mathrm{b}}$ & $(64) 4.14^{\mathrm{b}, \mathrm{c}}$ & $(64) 4.24^{\mathrm{b}, \mathrm{c}}$ \\
Qualification & & & & \\
Matric & $(61) 3.87^{\mathrm{a}, \mathrm{b}}$ & $(61) 3.84^{\mathrm{a}, \mathrm{b}}$ & $(61) 3.95^{\mathrm{a}, \mathrm{b}}$ & $(61) 3.82^{\mathrm{a}, \mathrm{b}}$ \\
Certificate & $(67) 4.16^{\mathrm{b}}$ & $(67) 4.21^{\mathrm{b}}$ & $(64) 4.16^{\mathrm{b}}$ & $(67) 4.15^{\mathrm{b}}$ \\
Diploma & $(107) 4.15^{\mathrm{b}}$ & $(107) 4.24^{\mathrm{b}}$ & $(107) 4.09^{\mathrm{b}}$ & $(107) 4.11^{\mathrm{b}}$ \\
Degree & $(97) 4.10^{\mathrm{b}}$ & $(97) 4.13^{\mathrm{b}}$ & $(97) 4.09^{\mathrm{b}}$ & $(97) 4.06^{\mathrm{b}}$ \\
Postgraduate & $(46) 4.19^{\mathrm{b}}$ & $(46) 4.23^{\mathrm{b}}$ & $(46) 4.21^{\mathrm{b}}$ & $(46) 4.13^{\mathrm{b}}$ \\
Other & $(25) 3.61^{\mathrm{a}}$ & $(25) 3.65^{\mathrm{a}}$ & $(25) 3.61^{\mathrm{a}}$ & $(25) 3.58^{\mathrm{a}}$ \\
\hline
\end{tabular}

Mean ${ }^{\text {HSD }}$ implies mean and a Tukey post hoc test for the ordinal categorical variable on the respective theoretical construct, showing the grouping of the variable where $a, b$ and $c$ represent statistically different groups.

than who had other qualifications (mean $=3.61, n=25$ ). It also shows that employees who worked at ADM experienced higher levels of job engagement (mean $=4.24 ; n=64$ ) than employees who worked at ANDM (mean $=3.58 ; n=73$ ).

When looking at the dimensions of job engagement separately, PE had statistically significant differences on the level of education $(F=4.97 ; p \leq 0.0001)$ and municipalities $(F=13.14 ; p \leq 0.0001)$. Employees who had a diploma qualification have significantly higher levels of PE than those who had other qualifications. It also shows that employees 
who worked at ADM had higher levels PE than employees who worked at ANDM.

In terms of EE, results show statistically significant differences on the level of education ( $F=2.31 ; p=0.043)$ and municipalities $(F=8.93 ; p \leq 0.0001)$. Employees who had a postgraduate qualification have significantly higher levels of EE than those who had other qualifications. It also shows that employees who worked at OR District Municipality had higher levels of EE than employees who worked at ANDM.

Lastly, CE showed significant differences with educational qualifications $(F=3.35 ; p=0.006)$ and municipalities $(F=$ 9.15; $p \leq 0.0001$ ). Employees who had a certificate qualification have significantly higher levels of CE than those who had other qualifications. It also shows that employees who worked at OR District Municipality had higher levels of CE than employees who worked at ANDM.

\section{Correlation analysis}

Firstly, it was necessary to check whether there was a linear relationship in the data that allowed for a linear regression analysis. To achieve this, the Pearson's bivariate correlation coefficient (one-tailed test) was used as shown in Table 4.

The results suggest that job engagement had moderate positive significant relationships with agreeableness $(r=0.39 ; p \leq 0.0001)$, conscientiousness $(r=0.40 ; p \leq 0.0001)$ and openness $(r=0.35 ; p \leq 0.0001)$. Extraversion had a weak, positive, significant linear relationship with job engagement $(r=0.12 ; p=0.009)$, whereas neuroticism had a weak negative significant linear relationship with job engagement $(r=-0.12 ; p=0.007)$. Conscientiousness, openness, extraversion and agreeableness were significantly positively related to all three job engagement dimensions. Neuroticism was negatively correlated with PE and EE; however, the study finds no significant correlation between neuroticism and CE $(r=-0.09 ; p=0.059)$.

\section{Simple linear regression}

It is also imperative to use simple linear regression models to test these hypothesised frameworks. For evaluating these models, the enter method was utilised. Durbin-Watson test for auto-correlation was used, and to test the assumption of homoscedasticity and normality of residuals, special plots (Q-Q plots) were used. Results of the simple linear regression models are presented in Table 5.

In terms of agreeableness, it resulted in a significant model $(F=71.53 ; p \leq 0.0001)$ and explained a significant amount of the variance in job engagement $\left(R^{2}=0.15\right.$; Adjusted $\left.R^{2}=0.15\right)$. The Durbin-Watson $d=1.62$ is between the two critical values of $1.5<d<2.5$, and therefore we can assume that there is no first-order linear auto-correlation in our linear regression data, which applies to all the big five personality traits. The unstandardised parameter estimates of the resultant model, both the constant term $\left(\beta_{0}=2.28 ; p \leq 0.0001\right)$ and the main effect of agreeableness trait $\left(\beta_{1}=0.50 ; p \leq 0.0001\right)$, are all
TABLE 4: Pearson correlation between personality traits and job engagement.

\begin{tabular}{lcccc}
\hline Personality traits & $\mathrm{JE}$ & $\mathrm{PE}$ & $\mathrm{EE}$ & $\mathrm{CE}$ \\
\hline Openness & & & & \\
Pearson correlation & $0.32 * *$ & $0.32 * *$ & $0.30 * *$ & $0.30^{* *}$ \\
sig. (one-tailed) & 0.0001 & 0.000 & 0.000 & 0.000 \\
$N$ & 358 & 358 & 362 & 353 \\
Conscientiousness & & & & \\
Pearson correlation & $0.40 * *$ & $0.39 * *$ & $0.37 * *$ & $0.35 * *$ \\
sig. (one-tailed) & 0.0001 & 0.000 & 0.000 & 0.000 \\
$N$ & 345 & 345 & 352 & 342 \\
Extraversion & & & & \\
Pearson correlation & $0.12 * *$ & $0.15 * *$ & $0.14 * *$ & $0.19 * *$ \\
sig. (one-tailed) & 0.0001 & 0.002 & 0.004 & 0.000 \\
$N$ & 364 & 364 & 369 & 362 \\
Agreeableness & & & & \\
Pearson correlation & $0.39 * *$ & $0.32 * *$ & $0.32 * *$ & $0.29 * *$ \\
sig. (one-tailed) & 0.009 & 0.000 & 0.000 & 0.000 \\
$N$ & 361 & 361 & 366 & 361 \\
Neuroticism & & & & \\
Pearson correlation & $-0.12 *$ & $-0.10^{*}$ & $-0.13 * *$ & -0.09 \\
sig. (one-tailed) & 0.007 & 0.036 & 0.007 & 0.059 \\
$N$ & 341 & 342 & 346 & 341 \\
\hline
\end{tabular}

$E E$, emotional engagement; $P E$, physical engagement; $C E$, cognitive engagement; JE, Job Engagegement.

*, Correlation is significant at the 0.05 level (one-tailed).

**, Correlation is significant at the 0.01 level (one-tailed)

statistically significant. Therefore, agreeableness does exert a positive effect on job engagement.

In terms of conscientiousness, the adjusted $R^{2}$ of our model is 0.162 , which means that the linear regression explains only $16.2 \%$ of the variance in the dependent variable. The resultant model revealed a significant fit $(F=77.25 ; p \leq 0.0001)$. Conscientiousness trait has a statistically significant positive effect on job engagement $\left(\beta_{1}=0.48 ; p \leq 0.0001\right)$. Openness to experience resultant model was significant $(F=56.30 ; p \leq$ $0.0001)$, and it also explained $12.3 \%$ of the variation in job engagement $\left(R^{2}=0.12\right.$; adjusted $\left.R^{2}=0.12\right)$. The regression coefficients are $\beta_{0}=2.41(p \leq 0.0001)$ and $\beta_{1}=0.48(p \leq 0.0001)$, respectively. Hence, openness to experience exerts a positive effect on job engagement.

Extraversion explained a small amount of the variance in job engagement $\left(R^{2}=0.01\right.$, adjusted $\left.R^{2}=0.01\right)$. The parameter estimates of the resultant model, both the constant term $\left(\beta_{0}=\right.$ $3.60 ; t=17.96 ; p \leq 0.0001)$ and the main effect of extraversion trait $\left(\beta_{1}=0.15 ; t=2.39 ; p=0.017\right)$, are all statistically significant. Therefore, extraversion does exert a positive effect on job engagement. Neuroticism trait explains only $1.5 \%$ of the variation in job engagement $\left(R^{2}=0.02\right.$; adjusted $\left.R^{2}=0.01\right)$. Parameter estimates show that both the constant term and neuroticism have a statistically significant effect on job engagement. The regression coefficients are $\beta_{0}=4.41(p \leq$ $0.0001)$ and $\beta_{1}=-0.12(p=0.014)$, respectively. Hence, neuroticism exerts a negative effect on job engagement.

\section{Discussion of the results}

Openness had a positive correlation with the overall job engagement. This may be because openness to experience has become a prior personality trait because of the rapidly 
TABLE 5: Simple linear regression model fit and summary for the big five personalities on job engagement.

\begin{tabular}{|c|c|c|c|c|c|}
\hline Source & Agreeableness & Conscientiousness & Openness & Extraversion & Neuroticism \\
\hline \multicolumn{6}{|l|}{ Model fit statistics } \\
\hline$F$-value $(\operatorname{Pr}>F)$ & $71.53 *(0.000)$ & $77.25 *(0.000)$ & $56.30 *(0.000 *)$ & $5.73 *(0.017)$ & $6.11 *(0.014)$ \\
\hline$N(\mathrm{df})$ & $402(1)$ & $402(1)$ & $402(1)$ & $402(1)$ & $402(1)$ \\
\hline \multicolumn{6}{|l|}{ Parameter estimates } \\
\hline$\beta_{0}$ (sig) & $2.28 *(0.000)$ & $2.34 *(0.000)$ & $2.41 *(0.000)$ & $3.60 *(0.000)$ & $4.41 *(0.000)$ \\
\hline$\beta_{1}$ (sig) & $0.50 *(0.000)$ & $0.48 *(0.000)$ & $0.48 *(0.000)$ & $0.15 *(0.017)$ & $-0.12 *(0.014)$ \\
\hline$R^{2}$ (adjusted $R^{2}$ ) & $0.15(0.15)$ & $0.16(0.16)$ & $0.12(0.12)$ & $0.01(0.01)$ & $0.02(0.01)$ \\
\hline Durbin-Watson test & 1.62 & 1.67 & 1.61 & 1.50 & 1.51 \\
\hline
\end{tabular}

Note: Independent variables: constant, agreeableness, conscientiousness, openness, extraversion and neuroticism. Dependent variable: job engagement.

*, Significant fit.

changing nature of current working life; hence, employees who adapt themselves to the changes can be more engaged in their job. This finding is consonant with that of Woods and Sofat (2013) who reported a positive and a statistically significant correlation between openness to experience and engagement $(r=0.28, p<0.01)$ with a relatively small practical size. Individuals with openness to experience have the tendency to be imaginative and curious as opposed to being concrete-minded and narrow thinking (Laher, 2010), thereby able to stimulate the level of employee engagement.

Conscientiousness was found to be positively correlated to job engagement and the three job engagement components. This can be explained because of the organisational skills, steadiness during hard times and a strong sense of responsibility engaged employees display whilst performing their roles. The results are supporting the findings of other researches (Van Daal, Donche, \& De Maeyer, 2014). Conscientious individuals have a tendency to be habitually careful, reliable, hardworking, well energised and purposeful, which makes them more engaged in their work.

Extraversion was found to be positively correlated to job engagement and its three job engagement components. The study results corroborate previous research performed by other researchers who found a positive correlation between job engagement and extraversion (Gulamali, 2017). This finding suggests that people who are highly assertive and sociable are most likely to work with great enthusiasm and inner drive to pursue others. An increased amount of extraversion experienced will result in an increase in job engagement as extroverts are characterised by displaying high levels of selfconfidence, energy and activity (Milfont \& Sibley, 2012).

Agreeableness was found to be positively correlated to job engagement. Similar results are also observed in the study conducted by Woods and Sofat (2013) among a sample of working adults in the UK and reported that agreeableness was positively correlated with engagement. The positive correlation between engagement and agreeableness suggests that participants have the proclivity to care, help and cooperate with others. The results are consistent with those by Akhtar, Boustani, Tsivrikos and Chamorro-Premuzic (2015) who found agreeableness as a significant predictor of job engagement. Agreeable employees can be more positive and motivated to resolve the problems and conflicts, which makes them more engaged in their job because they can save their energy and flow it to their work roles.

Neuroticism was found to be negatively correlated to job engagement. The study results are consistent with studies conducted by Reinke and Chamorro-Premuzic (2014) and Woods and Sofat (2013) who also found a negative correlation between neuroticism and job engagement. This may be because people high in neuroticism are likely to be distracted and put more energy into worrying about personal issues that are irrelevant to the task at hand. This naturally makes them less emotionally or cognitively available to perform the job.

Conscientiousness, agreeableness and openness accounted for $20.6 \%$ variance in job engagement. The study results are consistent with a study conducted by Shuckla, Aggarwal, Adhikari and Singh (2014) who found that almost $24 \%$ of employee engagement was explained by the personality of the employees on its own. They also found that conscientiousness, agreeableness and openness had a moderately positive relationship with employee engagement, whereas extraversion and neuroticism had a weak relationship with employee engagement, which is similar to this study results. In another study by Mroz and Kaleta (2016), all the five traits of personality accounted for $8 \%-15 \%$ of the variance in work engagement, whereas Gulamali (2017) found that $27.9 \%$ of the variance of job engagement was explained by the individual traits. On the other hand, Ziapour and Kianipour (2015) found that neuroticism and agreeableness predicted $4.9 \%$ of the variance of nurses' job engagement. The study does not support the results found by Yadav and Katiyar (2017) who found that extraversion and conscientiousness had a major impact on overall engagement and accounted for $57 \%$ change in employee engagement. In this study extraversion had a weak correlation with job engagement. These results are a bit contrary as extravert employees are most effective in jobs that require interpersonal relationships such as municipal workers. However, Moshoeu (2017) also found that extraversion did not act as significant predictors of employee engagement.

Job engagement had statistically significant differences on the level of education and municipalities. The study results in terms of education and job engagement are consistent with those conducted by Bell and Barkhuizen (2011) who found significant differences among job engagement, home 
language, ethnicity and educational qualification. This study showed that employees with a certificate were more engaged than employees who had diploma, degree, postgraduate and other educational qualification. This is consistent with previous research by Jackson and Rothmann (2004) who found that teachers with lower qualifications were more engaged than the others. However, the results contradict the discoveries of Barkhuizen and Rothmann (2006) who found academics with a doctoral degree to be more engaged than those with an honours degree.

The study results also show that there were significant differences between engagement and geographical location of employees. Employees who worked in certain municipalities such as ADM experienced more high levels of job engagement than employees working at ANDM. Amathole District is found in a big town and Alfred Nzo is situated in Mount Aliyff in what is considered a rural area which might affect how employees view their work. The results are in line with Lavoie (2014) who pointed out that location of a workplace has an impact on employee engagement when he found that most employees in big cities were more engaged. In addition, Gupta, Ganguli and Ponnam (2015) are of the view that location of appointment is a very crucial factor for engaging employees.

\section{Theoretical implications}

An important theoretical implication of this study is inherent in the subject matter of the research. Jin and McDonald (2016) suggested that employee engagement in the public enterprises is a topic that remains under-researched. This study adds to the scholarly research by providing results related to employee engagement under-researched sector. Additionally, to the best of the researcher's knowledge, the deployment of the JES and IPIP for this study marks the first application on the municipal workers in the ECP. The relationship between engagement and demographics is sometimes conflicting. A theoretical implication of this study was that, other than educational qualifications, none of the demographic variables were statistically significant predictors of employee engagement.

\section{Practical implications}

Currently, personality predictors are being used to select employees for several organisational outcomes. Findings from this study offer a deeper understanding of how an organisation can achieve the desired organisational goals. It can be noted that extraversion, conscientiousness, agreeableness and emotional stability have a positive effect on job engagement. Therefore, hiring employees based on personality predictors directly related to job performance will induce positive organisational outcomes, and so will hiring employees based on personality factors that relate to engagement.

An organisation should be cautious when designing jobs to minimise the cognitive, emotional and physical strain experienced by employees. Management should not overload employees with cognitive processing demands, or require them to perform extensive emotional labour in their positions without breaks, and should minimise the ergonomic jobrelated hazards present in their jobs.

It is important that management practitioners regularly measure and track employee engagement within the workforce. In doing so, the effectiveness of strategic efforts to increase employee engagement can be monitored and evaluated.

\section{Limitations and recommendations}

The quantitative approach to this study has implications for the research. The self-report questionnaires for personality and job engagement can lead to linear, subjectivity and faking because of factors such as a social desirability bias. It is recommended that further studies make use of different methodologies, such as qualitative and quantitative, which could provide more in-depth insights into the relationship between personality traits and employee engagement. As is the nature of research, a larger sample size could contribute to a greater generalisability of the current findings. Researchers have also noted the need for more longitudinal and experimental research study designs for research on personality and employee engagement (Rich et al., 2010). Personality traits can change over time as a result of external factors such as the environment of the place of employment, the experience gained within a role and the establishment of additional skills or expertise.

\section{Conclusion}

Increasing work engagement in a sustainable way remains a challenge despite years of research on the topic (Rothmann, 2017). The question remains as to why employees, when working under comparable conditions, display signs of job engagement, whereas others display a few or no signs of job engagement. It can be contributed to personality, and it cannot be ignored in the workplace especially because organisation represents a social system with many personalities interacting. Our theoretical validation is that certain behavioural and emotional styles related to personality traits will make it more likely that an individual will experience a state of engagement at the workplace. Organisations cannot change employees; however, they can capitalise on employees having certain traits that tend to facilitate a state of engagement. Therefore, the study provided guidance for selecting a new employee with the positive psychological capacity to successfully manage their engagement in a rapidly changing environment. Municipal workers need to be engaged in their work as this will enhance good service delivery, which will increase the socio-economic status of the citizens.

\section{Acknowledgements}

The authors thank Dr C.S. Marange from the University of Fort Hare Statistics Department for his assistance in data analysis.

\section{Competing interests}

The author(s) declare that they have no financial or personal relationships that may have inappropriately influenced them in writing this article. 


\section{Authors' contributions}

T.S.M. is the main author of the article. The article was written from the author's PhD study. Prof. T.Q. Mjoli is the PhD supervisor. Dr S.F. Chamisa assisted with conceptual contributions.

\section{Funding information}

University of Fort Hare Govan Mbeki Research and Development Centre assisted through a 3-year supervisory linked bursary.

\section{Data availability statement}

Data sharing is not applicable to this article as no new data were created or analysed in this study.

\section{Disclaimer}

The views expressed in this article are the authors' own work and not an official position of the institution or funder.

\section{References}

Agyemang, C.B., \& Ofei, S.B. (2013). Employee work engagement and organisational commitment: A comparative study in private and public-sector organisation in Ghana. European Journal of Business and Innovation Research, 1(4), 20-33.

Akhtar, R., Boustani, L., Tsivrikos, D., \& Chamorro-Premuzic, T. (2015). The engageable personality: Personality and trait El as predictors of work engagement. Personality and Individual Differences, 73(2015), 44-49. https://doi.org/10.1016/j.paid.2014.08.040

Alanoud, A., \& Amir, A.E. (2016). Exploring the relationship between personality and job performance: New approach. International Journal of Business and Management Invention, 5(12), 43-53.

American Psychology Association. (2017). Personality. American Psychological Association. Retrieved from http://www.apa.org/topics/personality.

Bailey, C., Madden, A., Alfes, K., \& Fletcher, L. (2017). The meaning, antecedents, and outcomes of employee engagement: A narrative synthesis. International Journal of Management Reviews, 19(1), 31-53.

Bakker, A., Demerouti, E., \& Brummelhius, L.T. (2012). Work engagement, performance and active learning: The role of conscientiousness. Journal of Vocational Behaviour, 80(2), 555-564. https://doi.org/10.1016/j.jvb.2011.08.008

Barkhuizen, E.N., \& Rothmann, S. (2006). Work engagement of academic staff in South African higher education institutions. Management Dynamics, 15(1), 38-48.

Bell, E., \& Barkhuizen, N. (2011). The relationship between barriers to change and the work engagement of employees in a South African property management company. SA Journal of Industrial Psychology/SA Tydskrif vir Bedryfsielkunde, 37(1), Art. \#935, 11 pages. https://doi.org/10.4102/sajip.v37i1.935

Business Dictionary. (2015). Employee engagement. Retrieved from: http://www. businessdictionary.com.

Crabtree, S. (2013). Worldwide, $13 \%$ of employees are engaged at work. Retrieved from www.gallup.com/poll/165269/worldwide/.

Crawford, E.R., LePine, J.A., \& Rich, B. (2010). Linking job demands and resources to employee engagement and burnout: A theoretical extension and meta-analytic test. Journal of Applied Psychology, 95(5), 834-848. https://doi.org/10.1037/ a0019364

Davis, R.J. (2013). The validation of a psychological battery for the selection of customer service agents in a South African commercial airline company. Pretoria: UNISA Press.

De Villiers, C. (2015). The relationships between emotional labour, the HEXACO personality traits, work engagement and burnout in the hospitality industry. Unpublished Master's Thesis, (Industrial Psychology) at Stellenbosch University. Retrieved from http://uir.unisa.ac.za/handle/10500/2622.

Devi, S. (2017). Impact of talent management on organisational performance: Role of employee engagement. International Journal of Management Studies 4(1) 17-27. ISSN(Print) 2249-0302 ISSN (Online) 2231-2528.

Fitzpatrick, S. (2017). From employee engagement to employee experience: Helping employees 'own' engagement. NHRMA 2017 Conference, The Ever-Change Waters of HR.

Gerlach, G., Herpertz, S., \& Loeber, S. (2015). Personality traits and obesity: A systematic review. Obesty Reviews, 16(1), 32-63. https://doi.org/10.1111/obr.12235

Goldberg, L.R. (1990). An alternative 'description of personality': The big-five factor structure. Journal of Personality and Social Psychology, 59(6), 1216-1229. https:// doi.org/10.1037/0022-3514.59.6.1216
Goldberg, L.R., Johnson, J.A., Eber, H.W., Hogan, R., Ashton, M.C., Cloninger, C.R., \& Gough, H.G. (2006). The international personality item pool and the future of public-domain personality measures. Journal of Research in Personality, 4O(1), 84-96. https://doi.org/10.1016/j.jrp.2005.08.007

Government Gazette. (1995). Labour relations act 66 of 1995. Cape Town: South African Government.

Government Gazette. (1998). Employment Equity Act 55 of 1998. Cape Town: South African Government.

Gulamali, D.I. (2017). Relationship between personality and work engagement: The role of individual traits and international experience. Unpublished Master's Thesis, Management with Specialization in Strategic Marketing at Universidade Católica Portuguesa.

Gupta, M., Ganguli, S., \& Ponnam, A. (2015). Factors affecting employee engagement in India: A study on offshoring of financial services. The Qualitative Report, 20(4) 498-515.

Habraken, M.M.P. (2013). Establishing employee engagement within a Dutch hotel. MSc thesis, Enschede: University of Twente.

Hale, R. (2016). Towards a better understanding of employee engagement: Factors that explain employee engagement. Doctoral Thesis, Capella University.

Handa, M., \& Gulati, A. (2014). Employee engagement does individual personality matter. Journal of Management Research, 14(1), 57-67.

Inceoglu, I., \& Warr, P. (2012). Personality and job engagement. Journal of Psychology, 10(4), 1-9.

Jackson, L.T.B., \& Rothmann, S. (2004). An adapted model of burnout for teachers in South Africa. South African Journal of Education, 25(2), 100-108.

Jin, M.H., \& McDonald, B. (2016). Understanding employee engagement in the public sector: The role of immediate supervisor, perceived organisational support and learning opportunities. The American Review of Public Administration, 47(8), 881-897. https://doi.org/10.1177/0275074016643817

Juan, A.B. (2010). Job demands and job resources. Burnout and engagement a multisample study. Journal of Organisational Behaviour, 7(25), 293-315.

Kahn, W.A. (1990). Psychological conditions of personal engagement and disengagement at work. Academy of Management Journal, 33(4), 692-724. https://doi.org/10.5465/256287

Kahn, W.A. (1992). To be fully there: Psychological presence at work. Human Relations, 45(4), 321-349. https://doi.org/10.1177/001872679204500402

Kamau, O., \& Sma, M. (2016). A critical review of literature on employee engagement concept. International Journal of Research in Social Sciences, 6(3), 1-8.

Laher, S. (2010). Using exploratory factor analysis in personality research: Bestpractice recommendations. SA Journal of Industrial Psychology, 36(1), Art. \#873, 7 practice recommendations. SA Journal of Indust
pages. https://doi.org/10.4102/sajip.v36i1.873

Lavoie, A. (2014). Does the company's location affect employee engagement? Retrieved from https://www.entrepreneur.com/article/237553.

Lebowitz, S. (2016). The 'Big 5' personality traits could predict who will and won't become a leader. Business Insider. Retrieved from http://www.businessinsider. com/big-five-personality-traits-predict-leadership-2016-12.

Leiter, M.P., \& Bakker, A.B. (2010). Work engagement: An introduction. In A.B. Bakker and M.P. Leiter (Eds.), Work engagement: $A$ handbook of essential theory and practice (pp. 1-9). London: Psychology Press.

Li, M., Wang, Z., Gao, J., \& You, X. (2017). Proactive personality and job satisfaction: The mediating effects of self-efficacy and work engagement in teachers. Current Psychology, 36(1), 48-55. https://doi.org/10.1007/s12144-015-9383-1

Maslach, C., \& Leiter, M.P. (1997). The truth about burnout: How organisations cause personal stress and what to do about it. San Francisco, CA: Jossey-Bass.

Men, L.R. (2015). Employee engagement in relation to employee-organisation relationship and internal reputation: Effects of leadership and communication. relationship and internal reputation:
Public Relations Journal, 9(2), 11-22.

Milfont, T.L., \& Sibley, C.G. (2012). The big five personality traits and environmental engagement: Associations at the individual and societal level. Journal of Environmental Psychology, 32(2), 187-195. https://doi.org/10.1016/j.jenvp.2011.12.006

Moshoeu, A. N. (2017). A model of personality traits and work-life balance as determinants of employee engagement. PhD in Literature and Philosophy. Unpublished. Pretoria: University of South Africa.

Mroz, J., \& Kaleta, K. (2016). Relationships between personality, emotional labor, work engagement and job satisfaction in service professions. International Journal of Occupational Medicine and Environmental Health, 29(5), 767-782. https://doi org/10.13075/ijomeh.1896.00578

Noesgaard, M.S. (2016). Work engagement among caregivers: Exploring the interplay between the individual and their context. PhD Dissertation, Department of Management, Aarhus: Aarhus University.

Ongore, O. (2013). Job engagement scale Turkish form's validity and reliability study. Kastamonu University. Journal of Economics and Administrative Sciences Faculty, 2(1), 50-60.

Pollitt, C., \& Bouckaert, G. (2011). Public management reform: A comparative analysis: NPM, governance and the Neo-Weberian State (3rd edn.). Oxford: Oxford University Press.

Reinke, K., \& Chamorro-Premuzic, T. (2014). When email use gets out of control: Understanding the relationship between personality and email overload and their impact on burnout and work engagement. Computers in Human Behaviour, 36(3) 502-509. https://doi.org/10.1016/j.chb.2014.03.075

Rich, B.L. (2006). Job engagement: Construct validation and relationships with job satisfaction, job involvement, and intrinsic motivation. Unpublished Doctora Dissertation, Gainesville: University of Florida.

Rich, B.L., Lepine, J.A., \& Crawford, E.R. (2010). Job engagement: Antecedents and effects on job performance. Academy of Management Journal, 53(3), 617-635. https://doi.org/10.5465/amj.2010.51468988 
Rothmann, S. (2017). Employee engagement. In L.G. Oades, M. Steger, A. Delle-Fave \& J. Passmore (Eds.), The Wiley-Blackwell handbook of the psychology of positivity and strengths-based approaches at work (pp. 317-341). Chichester: Wiley. and strengths-based approaches at work
https://doi.org/10.1002/9781118977620.ch18

Rothmann, S., \& Joubert, J.H.M. (2007). Job demands, job resources, burnout and work engagement of management staff at a platinum mine in the North-West Province. South African Journal of Business Management, 38(3), 49-61.

Saks, A.M., \& Gruman, J.A. (2014). What do we really know about employee engagement? Human Resource Development Quarterly, 25(2), 155-182. https:// doi.org/10.1002/hrdq. 21187

Schaufeli, W.B., Salanova, M., Gonzalez-roma, V., \& Bakker, A.B. (2002). The measurement of engagement and burnout: A confirmatory factor analytic approach. Journal of Happiness Studies, 3(1), 71-92. https://doi.org/10.1023/A:1015630930326

Shaban, S. (2018). Predicting big-five personality traits relation with employees' engagement in public sector in Egypt. International Journal of Business and Management Review, 6(1), 33-43.

Shuckla, S., Aggarwal, P., Adhikari, B., \& Singh, V. (2014). Relationship between employee engagement and big five personality factors: A study of online B2C e-commerce company. International Journal of Indian Management \& Strategy, 19(3), 26-34. https://doi.org/10.5958/0973-9343.2014.01233.2

South African Board for People Practices. (2014). Fact sheet 2014/1: Employing first time job market entrants. Johannesburg: SABPP.

Steger, M., Litman-Ovadia, H., Miller, M., Menger, L., \& Rothmann, S. (2013). Engaging in work even when it is meaningless: Positive affective disposition and meaningful work interact in relation to work engagement. Journal of Career Assessment, 21(2), 348-361. https://doi.org/10.1177/1069072712471517
Taylor, N., \& De Bruin, G.P. (2006). Basic traits inventory: Technical manual. Johannesburg: Jopie van Rooyen \& Partners.

Van Daal, T., Donche, V., \& De Maeyer, S. (2014). The impact of personality, goal orientation and self-efficacy on participation of high school teachers in learning activities in the workplace. Vocations and Learning, 7(1), 21-40. https://doi. org/10.1007/s12186-013-9105-5

Wilson, K. (2009). A survey of employee engagement. Unpublished PhD Thesis Faculty of Graduate School, University of Missouri-Columbia.

Wollard, K.K., \& Shuck, B. (2011). Antecedents to employee engagement: A structured review of the literature. Advances in Developing Human Resources, 13(4), 429-446. https://doi.org/10.1177/1523422311431220

Wood, J., Kim, W., \& Khan, G.F. (2016). Work engagement in organisations: A social network analysis of the domain. Scientometrics, 109(1), 317-336. https://doi. org/10.1007/s11192-016-1974-6

Woods, S.A., \& Sofat, J.A. (2013). Personality and engagement at work: The mediating role of psychological meaningfulness. Journal of Applied Social Psychology, 43(11), 2203-2221. https://doi.org/10.1111/jasp.12171

Yadav, A., \& Katiyar, D. (2017). Workforce diversity and individual differences: Implications for employee engagement. Indian Journal of Commerce \& Management Studies, 8(3), 7-15.

Ziapour, A., Kianipour, N. (2015). A study of the relationship between characteristic traits and employee engagement (a case study of nurses across Kermanshah, Iran in 2015). Journal of Medicine and Life, 8(3), 134-140. 